\title{
TIPOLOGI FASAD ARSITEKTUR TRADISIONAL MELAYU RIAU
}

\author{
Nadhira Aurelia ${ }^{1}$, Maria Immaculata Ririk Winandari ${ }^{2}$, Julindiani Iskandar ${ }^{3}$ \\ 1Jurusan Arsitektur, Fakultas Teknik Sipil dan Perencanaan, Universitas Trisakti, Jl. Kyai Tapa No.1, RT.6/RW.16, Tomang, \\ Kec. Grogol petamburan, Kota Jakarta Barat, DKI Jakarta, 11440 \\ 2Jurusan Arsitektur, Fakultas Teknik Sipil dan Perencanaan, Universitas Trisakti, Jl. Kyai Tapa No.1, RT.6/RW.16, Tomang, \\ Kec. Grogol petamburan, Kota Jakarta Barat, DKI Jakarta, 11440 \\ 3Jurusan Arsitektur, Fakultas Teknik Sipil dan Perencanaan, Universitas Trisakti, Jl. Kyai Tapa No.1, RT.6/RW.16, Tomang, \\ Kec. Grogol petamburan, Kota Jakarta Barat, DKI Jakarta, 11440
}

*aurelianadhira2@gmail.com

\begin{abstract}
ABSTRAK
Arsitektur Melayu Riau memiliki keunikan yang terletak pada aspek-aspek yang selalu berkaitan dengan adat dan agama masyarakat Melayu. Arsitektur Melayu memiliki peran penting dalam pelestarian budaya Melayu Indonesia di Riau karena merupakan batas terluar Indonesia dengan negara Singapura dan Malaysia. Mayoritas hotel resort di Riau tidak memiliki karakteristik arsitektur melayu melainkan karakteristik bangunan yang lebih modern. Penelitian ini dilakukan dengan metode tipologi yaitu dengan cara pengelompokan berdasarkan tipe atau elemen arsitektur melayu pada hotel resort dari konteks arsitektur tradisional Melayu Riau. Elemen yang diteliti terdiri dari muka bangunan (Fasad) Rumah Melayu adalah bumbung (atap), dinding, pintu dan tingkap (jendela) yang disetiap elemennya dikategorikan kembali sesuai dengan peletakan dan bentuk nya. Elemen yang mendominasi Arsitektur Melayu Riau pada atap berupa atap layar, pada dinding menggunakan kayu kaset, pada pintu berupa pintu kayu dua daun, pada jendela berupa jendela jejarak dan pada ornament berupa kaluk pakis dan lebang gantung pada lisplank dan ventilasi.
\end{abstract}

Keywords: Arsitektur Melayu, Fasad, Riau, Tradisional, Tipologi

\begin{abstract}
Riau Malay Architecture has a uniqueness that lies in aspects that are always related to the customs and religion of the Malay community. Malay architecture has an important role in the preservation of Indonesian Malay culture in Riau because it is Indonesia's outer boundary with Singapore and Malaysia. The majority of resort hotels in Riau do not have Malay architectural characteristics but rather more modern building characteristics. This research was conducted by typology method, namely by grouping based on the type or Malay architectural elements in resort hotels from the context of traditional Malay Malay architecture. The elements studied consist of the face of the building (facade) of the Malay house is a bumbung (roof), wall, door and window (window) which each element is categorized again according to the laying and shape. Elements that dominate Riau Malay Architecture on the roof are screen roofs, on the walls using wooden tapes, on the door in the form of two-leaf wooden doors, on a window in the form of a lined window and on the ornament in Kaluk Pakis and Lebah Gantung on list plank and ventilation.
\end{abstract}

Keywords: Malay Architecture, Facades, Riau, Traditional, Typology.. 


\section{PENDAHULUAN}

Arsitektur Melayu di Riau dapat dijadikan sebagai pengenalan budaya Indonesia kepada masyarakat baik dari dalam negeri maupun luar negeri karena berbatasan dengan negara Singapura dan Malaysia, tetapi perkembangan arsitektur Melayu di Riau terbilang sangat sedikit karena bangunan yang terdapat di daerah tersebut tidak lagi menggunakan karakteristik arsitektur Melayu yang ada. Mayoritas Hotel \& Resort di Riau Batam memiliki karakteristik bangunan yang lebih modern oleh karena itu pengembangan bangunan-bangunan dengan karakteristik Melayu Riau sangat diperlukan.

Arsitektur Melayu memiliki aspek yang dipengaruhi dan berkaitan dengan adat budaya dan agama. Bangunan tradisional Melayu adalah suatu bangunan yang utuh, yang dapat dijadikan tempat kediaman keluarga, musyawara, tempat beradat dan tempat berlindung. Dalam ranah adat bangunan tradisional Melayu Riau didirikan melalui tata cara yang sesuai dengan ketentuan adat, agar sebuah bangunan dapat disebut "Rumah sebenar rumah". Sedangkan, dalam ranah agama dalam membangun rumah tradisional Melayu syariat agama sangat diperhatikan seperti letak ruang kaum lelaki berbeda dengan ruang wanita.(Al Mudra, 2004)

Penelitian tentang arsitektur Melayu sebelum nya telah dilakukan diantaranya "identifikasi tipologi arsitektur rumah tradisional melayu di kabupaten langkat dan perubahannya" oleh Asnah Rumiawati dan Yuri Hermawan Prasetyo. "Studi tipomorfologi rumah melayu: inkrementasi ruang dan konstruksi" oleh Imanuddin dan
Yulianto P. Prihatmaji. "Langgam arsitektur melayu riau pada bangunan fasilitas umum di bengkalis objek studi museum sultan syarif kasim" oleh Alzena Felita.

\section{PUSTAKA}

Menurut Effendi (2009), bangunan tradisional Melayu adalah suatu bangunan yang utuh yang dapat dijadikan sebagai tempat kediaman keluarga, tempat bermusyawarah, tempat berketurunan, dan tempat berlindung bagi siapa saja yang memerlukannya. Bangunan tradisional melayu adalah bangunan utuh yang dapat dijadikan kediaman untuk keluarga, bermusyawara, beradat, berketurunan, dan tempat berlindung untuk yang memerlukan. Terdapat 4 elemen estetika dari arsitektur tradisonal Melayu, yang terdiri dari atap (bubung), pintu, jendela (tingkap), dan ornamen.

\section{Atap (Bubung)}

Masyarakat Melayu yang berada di daerah kepulauan Riau memiliki 3 macam bentuk rumah tradisional, yang dibedakan berdasarkan bentuk atapnya terdiri dari atap lipat kajang yaitu rumah dengan atap curam biasanya terletak pada rumah kediaman, lipat pandan yaitu rumah dengan atap mendatar dan atap layar yaitu rumah dengan tambahan atap dibagian bawahnya biasanya digunakan pada rumah balai (Mahyudin, 2004). Ruang atap di rumah tradisional Melayu memiliki ventilasi yang baik dengan penyediaan sambungan ventilasi dan panel dalam konstruksi atap. (Yuan, n.d.) 


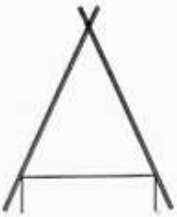

Atap Lipat Pandan

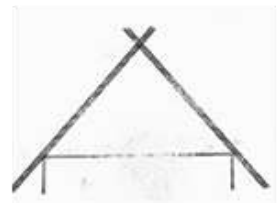

Atop Ligut Kajang

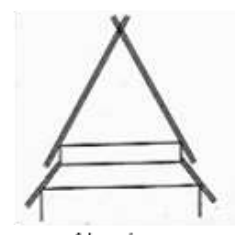

Atap Layar
Gambar 1. Jenis Atap Tradisional Melayu (Sumber: Mabyudin 2004)

\section{Dinding}

Penyusunan dinding rumah arsitektur Melayu dibagi menjadi 3 teknik yang pertama dinding susun sireh merupakan penyusunan secara horizontal, susunan dinding kaset merupakan teknik penyusunan secara vertikal dan dinding tindih kasih merupakan teknik penyusunan secara menumpuk. (Al Mudra, 2004)

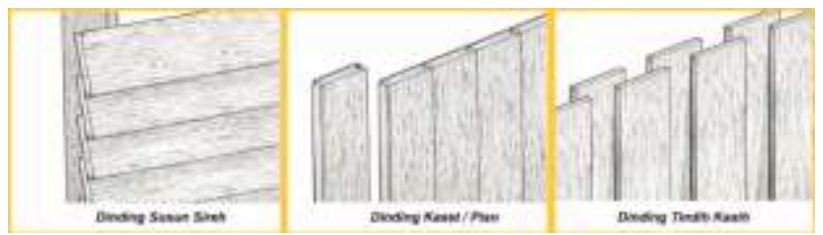

Gambar 2. Jenis-Jenis Dinding (Sumber :

bttps:/ / fachrimubammadabror.files.wordpress.com)

\section{Pintu}

Terdapat dua jenis pintu dalam Arsitektur Tradisional Melayu yaitu pintu depan (Ambang) dan pintu belakang (Telo). Pada umumnya, pintu sengaja dibuat rendah, sehingga orang-orang yang masuk atau keluar harus membungkuk yang memiliki arti bahwa orang yang ingin masuk atau keluar haru mengetahui adat dan tradisi setempat (Mahyudin, 2004).

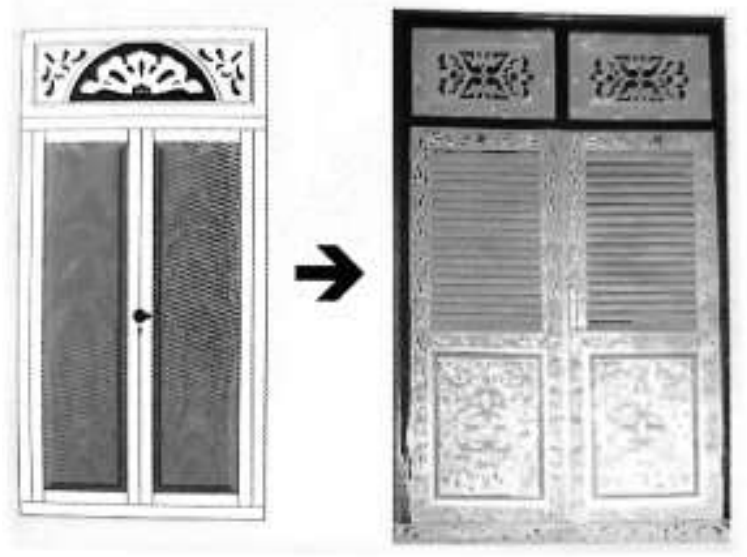

Gambar 3. Pintu Rumah Tradisional Melayu (Sumber : Mabyudin 2004)

\section{Jendela (Tingkap)}

Jendela rumah tradisional Melayu dibagi menjadi tiga komponen, yaitu bagian atas, tengah dan bawah. Komponen tengah dan bawah dapat dioperasikan dan dapat ditutup secara terpisah, sedangkan komponen atas diukir terbuka setiap saat untuk ventilasi. (Firrdhaus, Sahabuddin, \& Longo, 2017) 


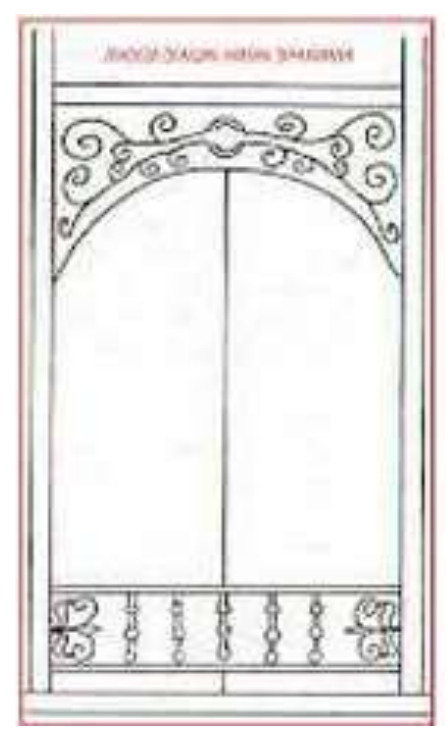

Gambar 4. Jejarak Jendela (Sumber : Mabyudin 2004) Ornamen

Motif dari ornamen Arsitektur Tradisional Melayu terdiri dari 4 jenis yang terdiri dari flora, fauna, alam, dan kepercayaan agama. Pada umumnya, jenis ornamen yang banyak digunakan adalah flora. Ornamen tersebut ditransformasi menjadi bentuk-bentuk tertentu, baik dengan bentuk yang sudah ada maupun dengan wujud bentuk yang baru. Ukiran yang berbentuk flora dimasukkan ke dalam tiga kelompok, yaitu : kelompok kaluk. pakis, bunga-bungaan, dan pucuk rebung. (Faisal, n.d.)
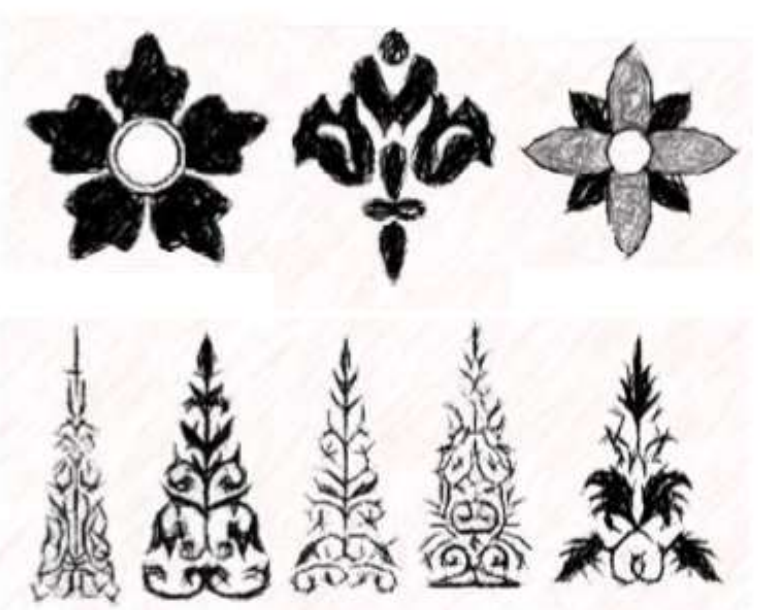

Gambar 5. Motif Bunga Manggis, Cengkih, dan Melur. (Sumber: Mabyudin 2004)

Ornamen fauna yang digunakan pada umumnya mengandung sifat atau filsafat tertentu atau yang berkaitan dengan mitos atau kepercayaan setempat. Misalnya, Semut Beriring karena bentuknya seperti semut yang berjalan beriringan, Itik Sekawan karena bentuknya mirip itik yang berjalan berkawan-kawan. (Faisal, n.d.)
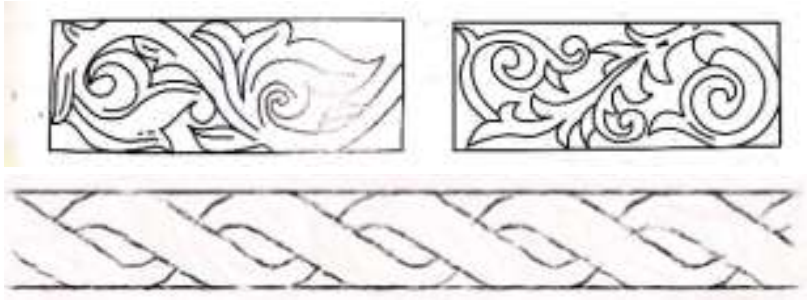

Gambar 6. Motif Kaluk Pakis \& Semut Beriring

(Sumber: Mabyudin 2004) 


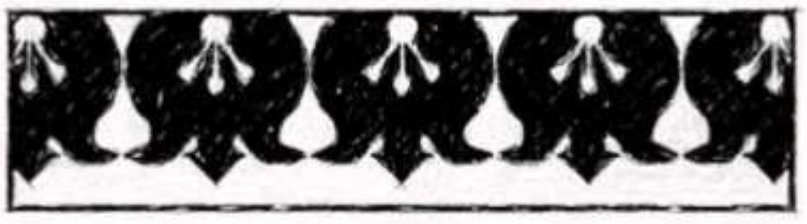

Gambar 7. Motif Lebah Gantung (Sumber : Mabyudin 2004)

Ornamen alam yang digunakan adalah ukiran bintangbintang. Sedangkan ornamen kepercayaan agama yang digunakan adalah ukiran-ukiran potongan ayat-ayat AlQur'an. (Faisal, n.d.)
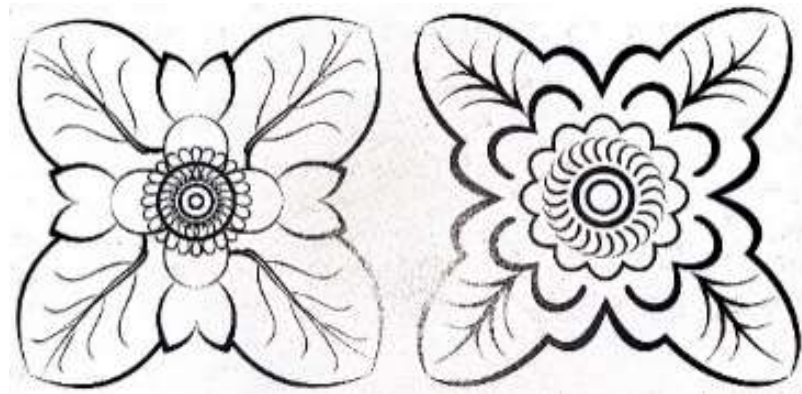

Gambar 8. Motif Bintang - Bintang (Sumber : Mabyudin 2004)

\section{METODE PENELITIAN}

Metode yang digunakan di penelitian ini adalah metode tipologi. Kasus Hotel Resort terdiri dari Hotel Resort Tempat Senang, Balai Melayu Museum dan KTM. Kasus tersebut akan di analisis dengan elemen-elemen arsitektur tradisional Melayu yang terdiri dari atap, dinding, pintu, jendela, ornamen.
Studi tentang tipologi menyangkut studi tentang tipe, yaitu mengkaji adanya kesamaan ciri khas secara formal dari sekelompok obyek. Tipologi juga dapat berarti sebagai studi tentang pengelompokan obyek (sebagaimodel) melalui kesamaan struktur atau suatu elemen. (Mentayani \& Andini, 2007)

Data kasus Hotel Resort didapat dan dikumpulkan dari website Hotel \& Resort masing-masing, kemudian data yang didapat di jabarkan menggunakan tabel sesuai dengan elemen-elemen yang dikelompokan sehingga terlihat dominansi pengaplikasian elemen pada banguan tersebut lalu temuan yang baru akan didapatkan.

\section{HASIL DAN PEMBAHASAN}

Unsur atap yang digunakan oleh 2 kasus Hotel \& Resort adalah bentuk limas. Bentuk lain yaitu lipat kajang digunakan di Tempat Senang Spa \& Resort. Bentuk yang digunakan tersebut, limas biasanya digunakan sebagai atap Rumah Kediaman dan lipat kajang yang biasanya digunakan untuk Rumah Balai memperkuat pernyataan oleh Mahyudin (2004) tentang penggunaan atap.
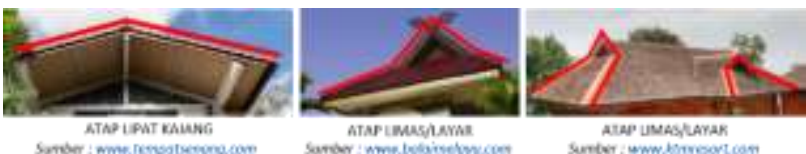

Gambar 9. Jenis Atap 3 Kasus (Sumber: Hasil Pengolahan Data) 
Unsur Dinding yang digunakan oleh dua kasus Hotel \& Resort adalah bentuk dinding kayu kaset. Bentuk lain yaitu dinding anyaman kelarai atau sireh. Bentuk yang digunakan tersebut, kayu kaset dan anyaman kelarai memperkuat pernyataan oleh Mahyudin (2004) tentang penggunaan dinding.

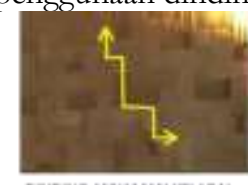
DNOWG ANYAMAN KELARAO

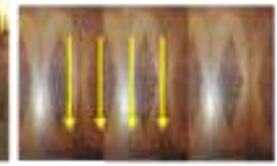

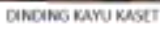

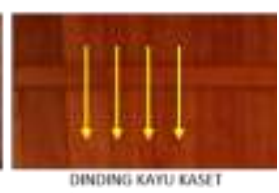

Sumber : minw itorecorticen

Gambar 10. Jenis Dinding 3 Kasus (Sumber : Hasil

Pengolahan Data)

Unsur pintu yang digunakan oleh dua kasus Hotel \& Resort adalah bentuk pintu kayu dua daun. Bentuk lain yaitu pintu kayu dengan satu daun. Bentuk yang digunakan tersebut pintu kayu dua daun dan satu daun memperkuat pernyataan oleh Mahyudin (2004) tentang penggunaan pintu.

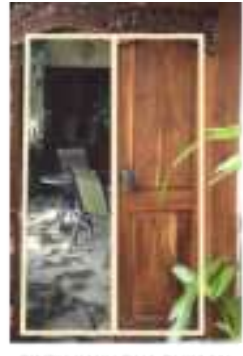

PINTU KAYU DUA BUKAAN

Gambar 11. Jenis Pintu 3 Kasus (Sumber : Hasil Pengolahan Data)

Unsur jendela yang digunakan oleh tiga kasus Hotel \& Resort adalah jendela jejarak dua bukaan. Bentuk yang digunakan tersebut, jendela jejarak dua bukaan memperkuat pernyataan oleh Sahabuddin (2012) tentang penggunaan jendela.
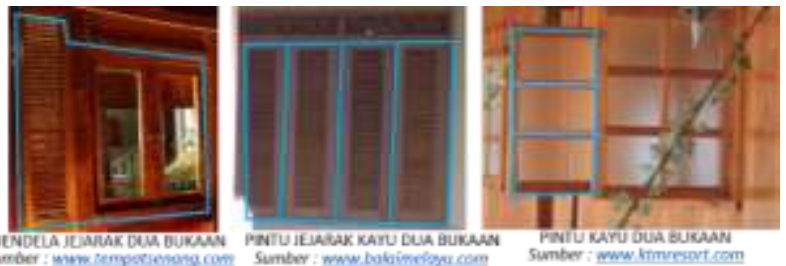

Gambar 12. Jenis Jendela 3 Kasus (Sumber : Hasil Pengolahan Data)

Unsur Ornamen hanya terdapat di dua dari tiga Hotel \& Resort. Ornamen yang digunakan terletak pada list plank dan ventilasi dengan ukiran kaluk pakis dan Lebah Gantung. Penggunaan motif tersebut memperkuat pernyataan oleh Faisal (2013) tentang penggunaan ornament.

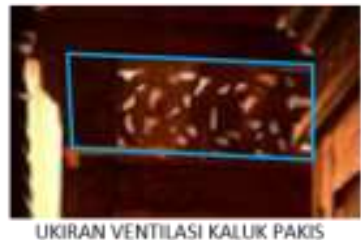

Sumber: www tempotsenong.com

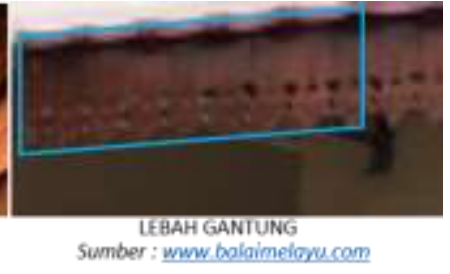

Sumber : wnw baliaimelorvecam
Gambar 13. Jenis Ornamen (Sumber: Hasil Pengolahan Data) 
Tabel 1. Elemen-Elemen Arsitektur Melayu Pada Hotel Resort

\begin{tabular}{|c|c|c|c|c|}
\hline Unsur & $\begin{array}{l}\text { Tempat Senang } \\
\text { Spa And Resort, } \\
\text { Batam. }\end{array}$ & $\begin{array}{l}\text { Balai Melayu Museum } \\
\text { Hotel, Yogyakarta. }\end{array}$ & Ktm Resort, Batam. & TEMUAN \\
\hline Atap & Atap Lipat Kajang & Atap Limas/Layar & Atap Limas/Layar & $\begin{array}{l}\text { Dominasi limas/Layar di } 2 \text { kasus, } \\
\text { dan lipat kajang di } 1 \text { kasus. }\end{array}$ \\
\hline Dinding & $\begin{array}{l}\text { Dinding Anyaman } \\
\text { Kelarai }\end{array}$ & Dinding Kayu Kaset & Dinding Kayu Kaset & $\begin{array}{l}\text { Dominasi Dinding Kayu Kaset di } \\
2 \text { kasus, dan Anyaman Kelarai di } \\
1 \text { kasus. }\end{array}$ \\
\hline Pintu & $\begin{array}{l}\text { Pintu Kayu Dua } \\
\text { Bukaan }\end{array}$ & Pintu Kayu Dua Bukaan & $\begin{array}{l}\text { Pintu Kayu Satu } \\
\text { Bukaan }\end{array}$ & $\begin{array}{l}\text { Dominasi Pintu Kayu dengan } \\
\text { Dua Bukaan di } 2 \text { kasus, dan } \\
\text { Pintu Kayu dengan Satu Bukaan } \\
\text { di } 1 \text { kasus. }\end{array}$ \\
\hline Jendela & $\begin{array}{l}\text { Jendela Jejarak } \\
\text { Dua Bukaan }\end{array}$ & $\begin{array}{l}\text { Pintu Jejarak Kayu Dua } \\
\text { Bukaan }\end{array}$ & $\begin{array}{l}\text { Pintu Kayu Dua } \\
\text { Bukaan }\end{array}$ & $\begin{array}{l}\text { Dominan Jendela Jejarak Dua } \\
\text { Bukaan di } 2 \text { kasus, dan Jendela } \\
\text { Kaca di } 1 \text { kasus. }\end{array}$ \\
\hline Ornamen & $\begin{array}{l}\text { Ukiran Ventilasi } \\
\text { Kaluk Pakis }\end{array}$ & Lebah Gantung & - & $\begin{array}{l}\text { Dominan menggunakan } \\
\text { ornament berupa : Lebah } \\
\text { Gantung dan Ukiran Ventilasi } \\
\text { Kaluk Pakis di } 2 \text { kasus, dan } 1 \\
\text { kasus tidak memiliki ornament. }\end{array}$ \\
\hline
\end{tabular}




\section{SIMPULAN}

Tipologi Arsitektur Melayu Riau untuk Hotel \& Resort diambil dari 3 kasus. Ketiga kasus tersebut adalah Hotel Balai Melayu Musium, KTM Resort dan Tempat Senang Spa \& Resort. Berdasarkan ketiga kasus tersebut bentuk unsur atap, dinding, pintu, jendela dan ornament yang mendominasi Hotel \& Resort yang dijadikan kasus adalah atap limas/layar, Dinding kayu kaset, Pintu kayu dengan dua bukaan, Jendela jejarak dua bukaan dan ornament lebah gantung pada lisplang dan ukiran ventilasi kaluk pakis.

Penggunaan bentuk atap layar yang mendominasi bangunan hotel \& resort disebabkan oleh bentuk unik atap layar itu sendiri, bangunan hotel \& resort cenderung menonjolkan bangunannya melalui bentuk atap yang menjadikannya suatu karakter di dalam kawasan hotel \& resort itu sendiri. Penggunaan bentuk dinding, pintu, dan jendela pada hotel \& resort yang ada karena ketiga bentuk dari masing-masing unsur memang digunakan pada bangunan hunian pada umumnya kemudian diaplikasikan pada desain hotel \& resort tersebut.

Penggunaan ornament pada hotel \& resort didasari pada penambahan estetika pada bangunan masing-masing, dan diaplikasikan sesuai dengan desain hotel \& resort masing-masing.

\section{UCAPAN TERIMAKASIH}

Dalam kerampungan pembuatan publikasi ilmiah ini, terdapat banyak bantuan dan bimbingan yang diberikan dari pembimbing sehingga publikasi ilmiah ini dapat terselesaikan dengan benar dan tepat waktu. Oleh sebab itu ucapan terimakasih diberikan kepada selaku pembimbing utama yaitu Ibu M.I Ririk Winandari dan juga selaku pembimbing pendamping yaitu Ibu Julindiani Iskandar, yang selalu memberi masukan dan dukungan dalam pengerjaan publikasi ilmiah ini.

\section{DAFTAR PUSTAKA}

Al Mudra, M. (2004). Rumah Melayu: Memangku Adat Menjemput Zaman. Yogyakarta: Adicita.

Faisal, G. (n.d.). SELEMBAYUNG SEBAGAI IDENTITAS KOTA PEKANBARU: KAJLAN LANGGAM ARSITEKTUR MELAYU.

Firrdhaus, M., Sahabuddin, M., \& Longo, C. G. (2017). Traditional $V$ alues and their Adaptation in Social Housing Design: Towards a New Typology and Establishment of " Air Ho .... 9(August), 31-45. https://doi.org/10.26687/archnet-ijar.v9i2.493

Mentayani, I., \& Andini, D. N. (2007). Tipologi dan Morfologi Arsitektur Suku Banjar di Kal-Sel. Retrieved from

https://www.scribd.com/document/407983190/ Chapter-II

Yuan, L. J. (n.d.). The traditional Malay house. 